\title{
Characteristics of Pepsin-Solubilised Collagen from the Skin of Splendid Squid (Loligo formosana)
}

\author{
Phanat Kittiphattanabawon, ${ }^{1}$ Sitthipong Nalinanon, \\ Soottawat Benjakul, ${ }^{3}$ and Hideki Kishimura ${ }^{4}$ \\ ${ }^{1}$ Department of Food Science and Technology, Faculty of Technology and Community Development, Thaksin University, \\ Phatthalung Campus, Phatthalung 93210, Thailand \\ ${ }^{2}$ Faculty of Agro-Industry, King Mongkut's Institute of Technology Ladkrabang, Ladkrabang, Bangkok 10520, Thailand \\ ${ }^{3}$ Department of Food Technology, Faculty of Agro-Industry, Prince of Songkla University, Hat Yai, Songkhla 90112, Thailand \\ ${ }^{4}$ Laboratory of Marine Products and Food Science, Research Faculty of Fisheries Sciences, Hokkaido University, \\ Hakodate, Hokkaido 041-8611, Japan
}

Correspondence should be addressed to Sitthipong Nalinanon; sitthipong.na@kmitl.ac.th

Received 12 October 2015; Accepted 7 December 2015

Academic Editor: Murat Senturk

Copyright (C) 2015 Phanat Kittiphattanabawon et al. This is an open access article distributed under the Creative Commons Attribution License, which permits unrestricted use, distribution, and reproduction in any medium, provided the original work is properly cited.

\begin{abstract}
Pepsin-solubilised collagen from the skin of splendid squid (SC) was isolated, partially purified by salt precipitation and dialysis prior to characterisation. The yield of SC was $75.3 \%$ (dry weight basis). SC with high purity was obtained as shown by the distinct UV absorption peak at $232 \mathrm{~nm}$ and high hydroxyproline content. Total sugar content of SC was $4.70 \%$ (dry weight basis), which was higher than that of collagen from calf skin (CC) $(1.45 \%$ dry weight basis) $(P<0.05)$. Based on SDS-PAGE and elution profile, SC might contain the mixed types of collagen (type SQ-I and type SQ-II), in which $\alpha$ - and $\beta$-chains were the major components. SC was rich in glycine and had high content of imino acids (189 residues/1000 residues). The degradation induced by chymotrypsin and lysyl endopeptidase was more pronounced in CC, compared with SC. The maximum transition temperature $\left(T_{\max }\right)$ of SC was $34.1^{\circ} \mathrm{C}$, which was about $7^{\circ} \mathrm{C}$ lower than that of CC. Fourier transform infrared spectra revealed that the triple-helical structure of SC was predominant with the copresence of carbohydrate moieties. Therefore, the skin of splendid squid, a byproduct from squid processing, can be an alternative source for collagen production.
\end{abstract}

\section{Introduction}

Collagen is the fibrous protein that contributes to the unique physiological functions of connective tissues in skins, tendons, bones, cartilages, and so forth and is associated with toughness of mammalian muscle [1-3]. The structural unit of collagen is tropocollagen, a rod-shaped protein consisting of three polypeptides units (called $\alpha$ chains) intertwined to form a triple-helical structure [4]. Each polypeptide chain forms a left-handed helix and consists of repeating triplets (Gly-X$Y)_{n}$, where $X$ and $Y$ are, with a high possibility, proline or hydroxyproline [5].

Generally, pig and cow skins and bones are the main sources of collagen and gelatin. The outbreak of bovine spongiform encephalopathy (BSE) has resulted in anxiety among users of cattle gelatin. Additionally, the collagen and gelatin obtained from pig skin and bones cannot be used due to the religious constraint [6]. As a consequence, the increasing attention of alternative sources for replacement of mammalian collagen has been paid. Seafood processing byproducts, particularly the skins, are alternative sources for collagen preparation. Collagens from several fish and cephalopods such as unicorn leatherjacket [7], arabesque greenling [8], brownbanded bamboo shark [2], cod [9], deepsea redfish [10], bigeye snapper [11, 12], black drum [5], sheephead seabream [5], octopus [13], and cuttlefish [14] have been isolated and characterised.

Squids have become an important fishery product in Thailand as well as other Southeast Asian countries and are mainly exported worldwide [15]. From the squid processing, 
the skin byproduct is generated in large quantity. It has been mainly used for fish meal or fertilizer with a low market value. Nagai et al. [14] reported that skin waste material from cuttlefish contained high amount of collagen. Hence, squid skin can be served as an alternative source of collagen. However, no information regarding the collagen from the skin of splendid squid (Loligo formosana) has been reported. Therefore, the objective of this study was to isolate and characterise the collagen from the skin of splendid squid ( $L$. formosana), a byproduct from squid processing.

\section{Materials and Methods}

2.1. Chemicals. Bovine haemoglobin, $\beta$-mercaptoethanol $(\beta \mathrm{ME})$, pepsin from porcine stomach mucosa (EC 3.4.23.1) (750 units/mg dry matter), and type I collagen from calf skin were purchased from Sigma Chemical Co. (St. Louis, MO, USA.). Coomassie Blue R-250 and $N, N, N^{\prime}, N^{\prime}$-tetramethyl ethylene diamine (TEMED) were procured from Bio-Rad Laboratories (Hercules, CA, USA). Bovine serum albumin was obtained from Fluka (Buchs, Switzerland). Highmolecular-weight protein marker was purchased from GE Healthcare UK Limited (Buckinghamshire, UK). TOYOPEARL CM-650M was purchased from Tosoh Corporation (Tokyo, Japan). $\alpha$-Chymotrypsin from bovine pancreas (EC 3.4.21.1), lysyl endopeptidase (EC 3.4.21.50) from Achromobacter lyticus, and type II, III, and V collagens from porcine cartilage, skin, and placenta, respectively, were obtained from Wako Pure Chemical Industries, Ltd. (Tokyo, Japan).

2.2. Preparation of Splendid Squid Skin. Splendid squid (Loligo formosana) were obtained from the dock in Samutsakhon, Thailand. The squid were packed in polyethylene bag, kept in ice with a solid/ice ratio of $1: 2(\mathrm{w} / \mathrm{v})$, and transported to the Faculty of Agro-Industry, King Mongkut's Institute of Technology Ladkrabang, Bangkok, Thailand, within $1 \mathrm{~h}$. All procedures were performed at $0-4^{\circ} \mathrm{C}$. Upon the arrival, the squid skin was removed and washed with cold water, drained, and cut into small pieces $\left(0.5 \times 0.5 \mathrm{~cm}^{2}\right)$ using the scissor. To remove noncollagenous proteins, the skin was mixed with $0.1 \mathrm{M} \mathrm{NaOH}$ using a sample/alkaline solution ratio of $1: 10(\mathrm{w} / \mathrm{v})$. The mixture was stirred continuously for $6 \mathrm{~h}$. The alkaline solution was changed every $2 \mathrm{~h}$. Then, the alkaline treated skin was washed with cold water until neutral or faintly basic $\mathrm{pH}$ of wash water was obtained. The treated skin was then defatted with $10 \%(\mathrm{v} / \mathrm{v})$ butyl alcohol with a solid/solvent ratio of $1: 10(\mathrm{w} / \mathrm{v})$ for $18 \mathrm{~h}$ and the solvent was changed every $6 \mathrm{~h}$. Defatted skin was then washed with 10 volumes of cold water for 3 times prior to lyophilisation.

\subsection{Isolation of Collagen from the Skin of Splendid Squid.} Pepsin-solubilised collagen from the skin of splendid squid was isolated following the method of Nalinanon et al. [12] with some modifications. All procedures were performed at $4^{\circ} \mathrm{C}$. To extract the collagen, the lyophilised skin was soaked in $0.5 \mathrm{M}$ acetic acid with a sample/solution ratio of $1: 250(\mathrm{w} / \mathrm{v})$ in the presence of porcine pepsin $(10 \mathrm{~g} / 100 \mathrm{~g}$ lyophilised skin). The mixture was gently stirred for $72 \mathrm{~h}$, followed by centrifugation at $20,000 \times \mathrm{g}$ for $1 \mathrm{~h}$ using the centrifuge (Sorvall Legend Mach 1.6R, Thermo Fisher Scientific, Germany). Then, the supernatant was immediately precipitated by the addition of $\mathrm{NaCl}$ to a final concentration of $2.6 \mathrm{M}$ in $0.05 \mathrm{M}$ Tris- $\mathrm{HCl}(\mathrm{pH} 7.5)$. The mixture was allowed to stand for $1 \mathrm{~h}$ for pepsin inactivation. The resultant precipitate was collected by centrifugation at $20,000 \times \mathrm{g}$ for $1 \mathrm{~h}$ and dissolved in 10 volumes of $0.5 \mathrm{M}$ acetic acid. The solution obtained was dialysed against 10 volumes of $0.1 \mathrm{M}$ acetic acid in a dialysis bag with a molecular weight cutoff of $14 \mathrm{kDa}$ for $48 \mathrm{~h}$ with the change of dialysis solution every $6 \mathrm{~h}$. Subsequently, the solution was dialysed with 60 volumes of distilled water. The changes of dialysis water were performed until neutral $\mathrm{pH}$ of dialysate was obtained. The dialysate was lyophilised and referred to as "pepsin-solubilised collagen from the skin of splendid squid, SC." SC was subjected to analyses. The yield of collagen was calculated based on the weight of SC in comparison with that of dry defatted skin.

\subsection{Characterisation of Collagen from the Skin of Splendid Squid}

2.4.1. Hydroxyproline Content. Collagen was dehydrated with acetone and then hydrolysed in $6 \mathrm{M} \mathrm{HCl}$ at $110^{\circ} \mathrm{C}$ for $24 \mathrm{~h}$ prior to the determination of hydroxyproline content using the colorimetric method as described by Nalinanon et al. [12]. The hydroxyproline content was calculated and expressed as mg/g collagen.

2.4.2. Total Sugar Content. Total sugar content of collagen was determined according to the phenol-sulfuric method as described by Fournier [16] with a slight modification. Collagen was dissolved in $0.5 \mathrm{M}$ acetic acid to obtain a final concentration of $6 \mathrm{mg} / \mathrm{mL}$ and further stirred until completely solubilised. To determine total sugar content, collagen sample $(250 \mu \mathrm{L})$ was mixed with $500 \mu \mathrm{L}$ of $4 \%$ phenol and $2.5 \mathrm{~mL}$ of $96 \%$ sulfuric acid. The mixture was allowed to stand at room temperature for $30 \mathrm{~min}$. The absorbance of the reaction mixture was then measured at $490 \mathrm{~nm}$. To calculate the concentration of sugar, the calibration curve was performed using D-glucose $(0-0.4 \mathrm{mg} / \mathrm{mL})$ as a standard. Total sugar content was calculated and expressed as \% (dry weight basis).

2.4.3. UV Absorption Measurement. Collagen was dissolved in $0.5 \mathrm{M}$ acetic acid to obtain a concentration of $1 \mathrm{mg} / \mathrm{mL}$. The solution was placed into a quartz cell with a path length of $1 \mathrm{~cm}$. UV absorption spectrum of collagen was measured using a spectrophotometer (UV-1800, Shimadzu, Kyoto, Japan). Prior to measurement, the base line was set with $0.5 \mathrm{M}$ acetic acid. The spectrum was obtained by scanning the wavelength in the range of 190-350 nm with a scan speed of $50 \mathrm{~nm} / \mathrm{min}$ at room temperature.

2.4.4. Differential Scanning Calorimetry (DSC). DSC analysis of collagen samples was carried out following the methods of Nalinanon et al. [12] with a slight modification. The samples 
were rehydrated by adding $0.05 \mathrm{M}$ acetic acid to dried samples at a solid/solution ratio of $1: 40(\mathrm{w} / \mathrm{v})$. The mixture was allowed to stand for 2 days at $4^{\circ} \mathrm{C}$. DSC analysis was performed using a differential scanning calorimeter (Model DSC 7, Norwalk, CT, USA). Temperature calibration was done using the indium thermogram. The collagen solutions $(5-10 \mathrm{mg})$ were accurately weighed into aluminium pans and sealed. The samples were scanned at $1^{\circ} \mathrm{C} / \mathrm{min}$ over the range of $20-50^{\circ} \mathrm{C}$ using iced water as the cooling medium. An empty pan was used as the reference. The maximum transition temperature $\left(T_{\max }\right)$ was estimated from the DSC thermogram.

2.4.5. Amino Acid Analysis. Collagen was hydrolysed under reduced pressure in $4.0 \mathrm{M}$ methanesulfonic acid containing $0.2 \%(\mathrm{v} / \mathrm{v}) 3-2\left(2\right.$-aminoethyl)indole at $115^{\circ} \mathrm{C}$ for $24 \mathrm{~h}$. The hydrolysates were neutralised with $3.5 \mathrm{M} \mathrm{NaOH}$ and diluted with $0.2 \mathrm{M}$ citrate buffer ( $\mathrm{pH} 2.2$ ). An aliquot of $0.4 \mathrm{~mL}$ was applied to an amino acid analyser (MLC-703; Atto Co., Tokyo, Japan).

2.4.6. SDS-Polyacrylamide Gel Electrophoresis (SDS-PAGE). SDS-PAGE was performed by the method of Laemmli [17]. The samples were mixed with $5 \%(\mathrm{w} / \mathrm{v})$ SDS and heated at $85^{\circ} \mathrm{C}$ for $1 \mathrm{~h}$. The mixtures were then centrifuged at $8,500 \times \mathrm{g}$ for $5 \mathrm{~min}$ to remove undissolved debris. Solubilised samples were mixed at $1: 1(\mathrm{v} / \mathrm{v})$ ratio with the sample buffer (0.5 M Tris- $\mathrm{HCl}, \mathrm{pH} 6.8$, containing $4 \%$ (w/v) SDS, 20\% (v/v) glycerol) in the presence of $10 \%(\mathrm{v} / \mathrm{v}) \beta \mathrm{ME}$. Samples $(15 \mu \mathrm{g}$ protein) were loaded onto a polyacrylamide gel made of $7.5 \%$ or $5 \%$ separating gel and $4 \%$ stacking gel and subjected to electrophoresis at a constant current of $15 \mathrm{~mA} /$ gel, using a Mini-PROTEAN II unit (Bio-Rad Laboratories Inc., Richmond, CA, USA). After electrophoresis, gels were fixed with a mixture of $50 \%(\mathrm{v} / \mathrm{v})$ methanol and $10 \%(\mathrm{v} / \mathrm{v})$ acetic acid for $45 \mathrm{~min}$, followed by staining with $0.05 \%(\mathrm{w} / \mathrm{v})$ Coomassie Blue R-250 in $15 \%(\mathrm{v} / \mathrm{v})$ methanol and $5 \%(\mathrm{v} / \mathrm{v})$ acetic acid for $3 \mathrm{~h}$. Finally, gels were destained with the mixture of $30 \%(\mathrm{v} / \mathrm{v})$ methanol and $10 \%(\mathrm{v} / \mathrm{v})$ acetic acid for $45 \mathrm{~min}$. High-molecular-weight protein markers (GE Healthcare UK Limited, Buckinghamshire, UK) were used to estimate the molecular weight of proteins. Gels were imaged using a Canon image scanner (CanoScan LiDE100, Canon Inc., Tokyo, Japan).

2.4.7. TOYOPEARL CM-650 Column Chromatography. TOYOPEARL CM-650 column chromatography was carried out according to the method of Kittiphattanabawon et al. [2] and Nalinanon et al. [8] with a slight modification. SC $(20 \mathrm{mg})$ were dissolved in $5 \mathrm{~mL}$ of starting buffer $(50 \mathrm{mM}$ sodium acetate buffer, $\mathrm{pH} 4.8$ containing $2 \mathrm{M}$ urea) and incubated at $60^{\circ} \mathrm{C}$ for $30 \mathrm{~min}$. The mixtures were centrifuged at $20,000 \times \mathrm{g}$ at room temperature $\left(25-26^{\circ} \mathrm{C}\right)$ for $30 \mathrm{~min}$. The supernatant was applied onto a TOYOPEARL CM-650 M column (1.0 $\times 5.0 \mathrm{~cm}$ ) previously equilibrated with 10 volumes of the starting buffer at a flow rate of $30 \mathrm{~mL} / \mathrm{h}$. After loading, the unbound proteins were washed by the same buffer until $\mathrm{A}_{230}$ was less than 0.05 . Elution was achieved with a linear gradient of $0-0.2 \mathrm{M} \mathrm{NaCl}$ in the same buffer at a flow rate of $30 \mathrm{~mL} / \mathrm{h}$ with a total volume of $100 \mathrm{~mL}$. The eluant was monitored at $230 \mathrm{~nm}$ and fractions $(2 \mathrm{~mL})$ were collected. The selected fractions were subjected to SDS-PAGE using 5\% separating gel and $4 \%$ stacking gel as previously described.

2.4.8. Fourier Transform Infrared (FTIR) Spectroscopy. Spectra of collagens were obtained by using a Bruker Model EQUINOX 55 FTIR spectrometer (Bruker, Ettlingen, Germany) equipped with a deuterated l-alanine triglycine sulfate (DLATGS) detector. The Horizontal Attenuated Total Reflectance Accessory (HATR) was mounted into the sample compartment. The internal reflection crystal (Pike Technologies, Madison, WI, USA), which was made of zinc selenide, had a $45^{\circ}$ angle of incidence to the IR beam. Spectra were acquired at a resolution of $4 \mathrm{~cm}^{-1}$ and the measurement range was $4000-600 \mathrm{~cm}^{-1}$ (mid-IR region) at room temperature. Automatic signals were collected in 32 scans at a resolution of $4 \mathrm{~cm}^{-1}$ and were ratioed against a background spectrum recorded from the clean, empty cell at $25^{\circ} \mathrm{C}$. Analysis of spectral data was carried out using the OPUS 3.0 data collection software program (Bruker, Ettlingen, Germany).

2.4.9. Peptide Mapping. Peptide mappings of SC and CC were performed according to the method of Nalinanon et al. [8] with a slight modification.

(1) Lysyl Endopeptidase Hydrolysis. The freeze-dried samples ( $3 \mathrm{mg}$ ) were dissolved in $0.5 \mathrm{~mL}$ of $0.1 \mathrm{M}$ sodium phosphate, $\mathrm{pH} 7.2$ containing $5 \%(\mathrm{w} / \mathrm{v})$ SDS. After the addition of $20 \mu \mathrm{L}$ of the same buffer containing $0.1 \mu \mathrm{g}$ of lysyl endopeptidase from A. lyticus to collagen solutions, the reaction mixture was incubated at $37^{\circ} \mathrm{C}$ for $60 \mathrm{~min}$. The reaction was terminated by subjecting the reaction mixture to boiling water for $10 \mathrm{~min}$.

(2) Chymotryptic Hydrolysis. The freeze-dried samples (3 mg) were suspended in $0.5 \mathrm{~mL}$ of $50 \mathrm{mM}$ Tris- $\mathrm{HCl}, \mathrm{pH} 8.0$, containing $10 \mathrm{mM} \mathrm{CaCl}_{2}$. The collagen mixture was preincubated at $37^{\circ} \mathrm{C}$ for $15 \mathrm{~min}$. Then, $20 \mu \mathrm{L}$ of the same buffer containing $5 \mu \mathrm{g}$ of chymotrypsin was added to collagen solution. The mixture was then incubated at $37^{\circ} \mathrm{C}$ for $5 \mathrm{~min}$. The reaction was terminated by adding $0.5 \mathrm{~mL}$ of $5 \%(\mathrm{w} / \mathrm{v}) \mathrm{SDS}\left(85^{\circ} \mathrm{C}\right)$ to the reaction mixture and boiling for $10 \mathrm{~min}$.

Peptides generated by the protease digestion were subjected to SDS-PAGE using 7.5\% running gel and $4 \%$ stacking gel in the same manner as previously described.

2.5. Statistical Analysis. Experiments were performed in triplicate. Data were presented as means \pm standard deviation and a probability value of $<0.05$ was considered significant. For pair comparison, $t$-test was used. SPSS statistic programme (SPSS 11.0 for Windows, SPSS Inc., Chicago, IL, USA) was used for data analysis.

\section{Results and Discussion}

3.1. Yield and Characteristics of SC. Collagen from squid skin was extracted with the aid of pepsin with the yield 
TABLE 1: Yield and characteristics of collagen from the skin of splendid squid (SC) and type I collagen from calf skin (CC) ${ }^{\dagger}$.

\begin{tabular}{lcc}
\hline Characteristics & SC & CC \\
\hline Yield (\% dry weight) & $75.3 \pm 1.20$ & - \\
Hydroxyproline (mg/g dry sample) & $98.5 \pm 1.43^{\mathrm{a} \neq}$ & $104 \pm 2.45^{\mathrm{b}}$ \\
Total sugar content $(\%$ dry weight) & $4.70 \pm 0.39^{\mathrm{b}}$ & $1.45 \pm 0.20^{\mathrm{a}}$ \\
UV absorption peak (nm) & $232 \pm 0.30^{\mathrm{a}}$ & $232 \pm 0.13^{\mathrm{a}}$ \\
$T_{\max }\left({ }^{\circ} \mathrm{C}\right)$ & $34.1 \pm 0.10^{\mathrm{a}}$ & $40.8 \pm 0.20^{\mathrm{b}}$ \\
$\Delta H(\mathrm{~J} / \mathrm{g})$ & $0.66 \pm 0.04^{\mathrm{a}}$ & $1.20 \pm 0.07^{\mathrm{b}}$ \\
\hline
\end{tabular}

${ }^{\dagger}$ Mean \pm SD from triplicate determinations.

${ }^{\ddagger}$ Different letters ( $\mathrm{a}$ and $\mathrm{b}$ ) in the same row indicate the significant difference $(P<0.05)$.

of $75.3 \%$ (dry wt.) (Table 1). Yield was markedly increased in comparison with acid solubilised collagen $(6.27 \%)$ (data not shown). The result indicated that pepsin was effective in increasing the extraction efficacy of collagen. Hydroxyproline content in SC (98.5 mg/g dry wt.) was lower than that of CC (104 mg/g dry wt.). Rigby [18] reported that hydroxyproline contents vary with species, environment, and body temperature of fish. Both SC and CC contained the carbohydrate. Glucose and galactose are attached to hydroxylysine residues of the peptide chain by O-glycosidic bonds to form 2-O$\alpha$-D-glucosyl-O- $\beta$-D-galactosyl-hydroxylysine and $\mathrm{O}-\beta$-Dgalactosyl-hydroxylysine [19]. Glycosylgalactosyl hydroxylysine in collagen from sea cucumber was reported [20]. From UV-Vis spectra, both collagens had the same absorption peak at $232 \mathrm{~nm}$. Very low absorbance at $280 \mathrm{~nm}$ of both SC and CC (data not shown) indicated the absence of noncollagenous proteins. Collagen commonly has a low amount of tyrosine, which could absorb UV-light at $280 \mathrm{~nm}$ [9]. Thus, collagens from the skin of splendid squid were obtained with negligible contamination of other proteins.

Based on thermal properties analysis, the maximum transition temperature $\left(T_{\max }\right)$ and total denaturation enthalpy $(\Delta H)$ of SC and CC are presented in Table $1 . T_{\max }$ and $\Delta H$ of SC $\left(T_{\max }=34.1^{\circ} \mathrm{C} ; \Delta H=0.656 \mathrm{~J} / \mathrm{g}\right)$ were lower than those found in $\mathrm{CC}\left(T_{\max }=40.8^{\circ} \mathrm{C} ; \Delta H=1.204 \mathrm{~J} / \mathrm{g}\right)$ $(P<0.05)$. This might be owing to the lower content of its imino acids (hydroxyproline and proline) (Table 2). SC showed higher thermal stability than collagens from cold water fish, including $\operatorname{cod}\left(15^{\circ} \mathrm{C}\right)$ and deep-sea redfish $\left(16.1^{\circ} \mathrm{C}\right)$ $[6,10]$. Thermal stability of SC was similar to that of collagen from tropical fish, including brownbanded bamboo shark skin $\left(34.4^{\circ} \mathrm{C}\right)$, blacktip shark skin $\left(34.2^{\circ} \mathrm{C}\right)$, black drum skin $\left(34.2^{\circ} \mathrm{C}\right)$ and sheephead seabream $\left(34^{\circ} \mathrm{C}\right)[2,5,21]$. The difference in thermal properties amongst collagens from mammal, tropical fish, and cold water fish was correlated with their imino acid content (proline and hydroxyproline), body temperature, and environmental temperature [11, 22, 23]. Thermal stability of collagen is associated with the restriction of the secondary structure of the polypeptide chain governed by the pyrrolidine rings of proline and hydroxyproline and partially by the hydrogen bonding through the hydroxyl group of hydroxyproline [24-26].
TABLE 2: Amino acid composition of collagen from the skin of splendid squid (SC) and type I collagen from calf skin (CC).

\begin{tabular}{lcc}
\hline Amino acid & SC & CC \\
\hline Alanine & 88 & 119 \\
Arginine & 56 & 51 \\
Aspartic acid/asparagine & 57 & 45 \\
Cysteine & 0 & 0 \\
Glutamic acid/glutamine & 83 & 75 \\
Glycine & 331 & 330 \\
Histidine & 6 & 5 \\
Isoleucine & 19 & 11 \\
Leucine & 28 & 23 \\
Lysine & 12 & 26 \\
Hydroxylysine & 17 & 7 \\
Methionine & 14 & 6 \\
Phenylalanine & 11 & 3 \\
Hydroxyproline & 91 & 94 \\
Proline & 98 & 121 \\
Serine & 35 & 39 \\
Threonine & 25 & 18 \\
Tyrosine & 5 & 3 \\
Tryptophan & 1 & 3 \\
Valine & 23 & 215 \\
\hline Total & 1000 & \\
Imino acids & 189 & \\
\hline Imino & & \\
\hline
\end{tabular}

${ }^{\mathrm{a}}$ Imino acids include proline and hydroxyproline.

3.2. Protein Patterns and Subunit Composition of SC. Protein patterns of SC determined under reducing condition are shown in Figure 1. SC comprised $\alpha$ - and $\beta$-chains as major components with low content of $\gamma$-chain. Protein pattern of SC was quite different from that of collagen types I, II, III, and V. Two different $\alpha$-chains were presented in SC and $\alpha$ chain with $\mathrm{MW}$ of $127 \mathrm{kDa}$ was the dominant component. It indicated that SC might contain at least two types of collagen. From the elution profiles of SC on the TOYOPEARL CM$650 \mathrm{M}$ column (Figure 2), single peak containing different collagen components was obtained. There were four distinct $\alpha$-chains (bands a, b, c, and d) and cross-linked components ( $\beta$ - and $\gamma$-chains) (fraction numbers 26 and 28 ). The collagen components, especially $\alpha$-chain, of SC were in accordance with those of collagen from the skin of squid (Todarodes pacificus), which contained two types of collagen, type SQI and type SQ-II [27]. Therefore, SC most likely consisted of type SQ-I and type SQ-II. However, the components of SC in the present study were quite different from those found in collagen from the skin of octopus (Octopus vulgaris) and cuttlefish (Sepia lycidas), which comprised two distinct $\alpha$ chains, $\alpha 1$ and $\alpha 2$, with a molar ratio of $2: 1[14,28]$.

3.3. Amino Acid Composition of SC and CC. The amino acid composition of SC and CC expressed as residues per 1000 total amino acid residues is shown in Table 2. Both collagens had glycine as their major amino acid (330-331 residues/1000 residues) and are rich in alanine (88-119 residues/1000 


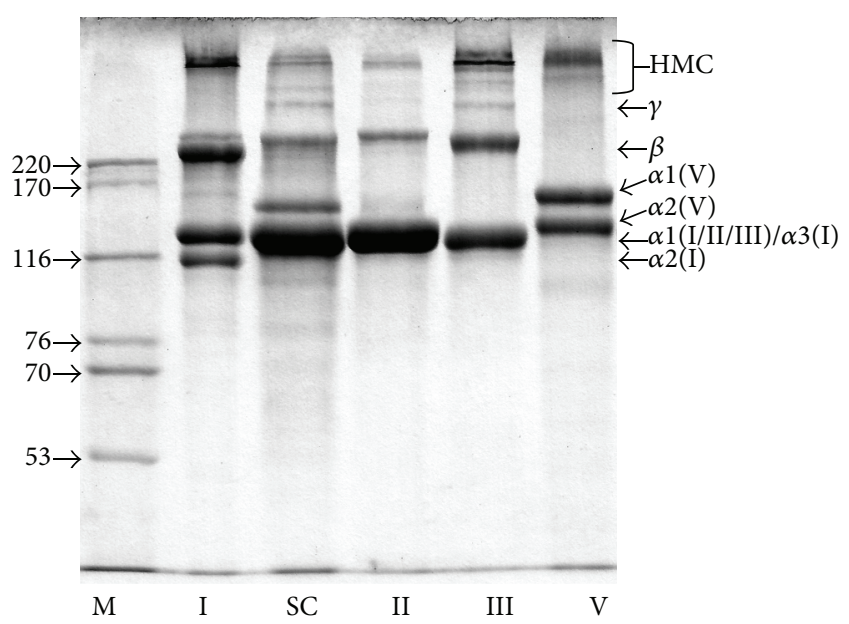

FIGURE 1: SDS-PAGE pattern of collagen from the skin of splendid squid (SC) under reducing condition. HMC, M, I, II, III and $\mathrm{V}$ denote high-MW cross-linked components, high-MW protein markers, and collagen type I, type II, type III, and type V, respectively.
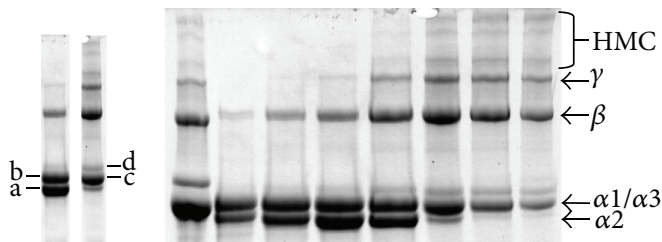

\section{$\overline{24} \overline{28}$}
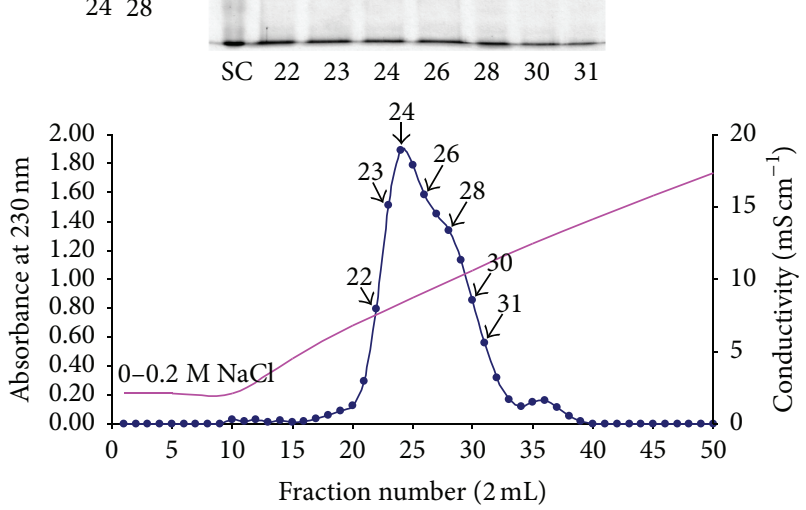

FIGURE 2: Elution profile of collagen from the skin of splendid squid (SC) on the TOYOPEARL CM-650 M ion-exchange column. The fractions indicated by numbers were examined by SDS-PAGE using $5 \%$ separating gel and 4\% stacking gel. HMC denotes high-MW cross-linked component.

residues), proline (98-121 residues/1000 residues), and hydroxyproline (91-94 residues/1000 residues). Generally, glycine is about one-third of the total amino acid residues. Proline and hydroxyproline constitute about one-fifth and alanine is for about one-ninth of the total amino acids in collagen [29]. Furthermore, they had relatively low contents of methionine, lysine, phenylalanine, hydroxylysine, histidine, tyrosine, and tryptophan and no cysteine. When comparing amino acid composition between both collagens,

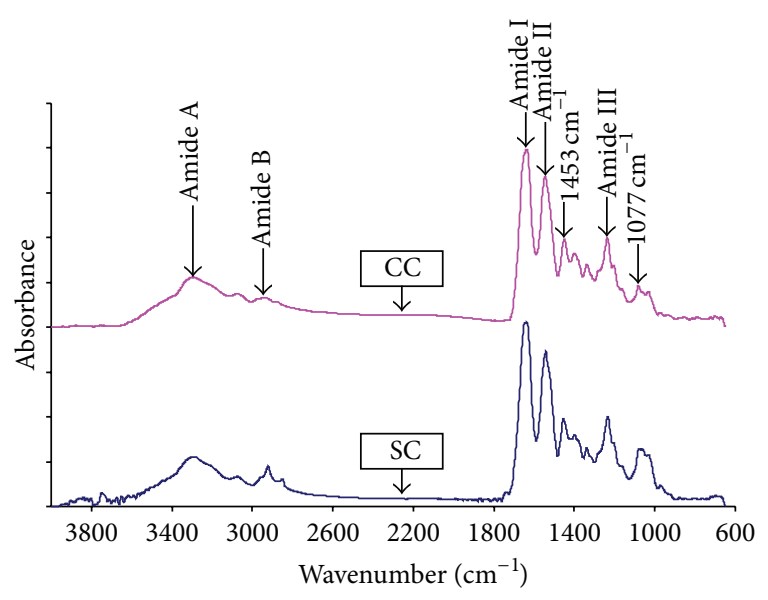

FIGURE 3: FTIR spectra of collagen from the skin of splendid squid (SC) and type I collagen from calf skin (CC).

SC had much lower content of alanine and proline. The results were in agreement with collagen from octopus arm (Callistoctopus arakawai) and outer skin of cuttlefish (Sepia lycidas) $[13,14]$. Additionally, the same results were also observed in collagen from the skin of other fish species such as arabesque greenling [8], blacktip and brownbanded bamboo shark [2, 21], bigeye snapper [11, 24], and unicorn leatherjacket [30]. The imino acid content (proline + hydroxyproline) of SC was 189 residues $/ 1000$ residues, which was much lower than that of calf skin collagen (215 residues/1000 residues). However, it was much higher than that of skin collagen from cold water fish species (154-160 residues/1000 residues) such as cod [9], arabesque greenling [8], and deep-sea redfish [10]. The imino acid of fish collagens has been known to correlate with the water temperature of their normal habitat [1]. The sensitivity of collagen to heat is associated with its superhelical structure that is maintained by the conformational restrictions imposed by the pyrrolidine rings of the imino acids (hydroxyproline and proline) [26]. Hydroxyproline plays an important role in stabilization of the helix structure by preventing rotation of the N-C bond [1]. With reference to hydroxyproline content, the conversion factor of hydroxyproline to collagen from the skin of splendid squid was calculated to be 9.20 . The conversion factors of collagen from other sources such as ornate threadfin bream (12.72) [31] and Baltic cod skin (14.7) [6] have been reported. This factor might be useful for estimation of the collagen content in raw material and the yield of extraction as well as purity assessment of resultant collagen.

3.4. Fourier Transform Infrared (FTIR) Spectra of SC and CC. FTIR spectra in the range $4000-650 \mathrm{~cm}^{-1}$ of SC and CC are presented in Figure 3. SC exhibited FTIR spectrum in which the absorption bands were situated in the amide band region, including the peak of amide I, amide II, amide III, amide $\mathrm{A}$, and amide B. The wavenumber of each amide band was quite similar to that found in collagens from the skin of other fish $[2,8,21,24,32]$. FTIR spectra of both collagens 
were slightly different. It might be caused by the difference in extraction process used, their amino acid compositions, and amino acid sequence between both collagens. Amide A bands of SC and CC were observed at 3290 and $3296 \mathrm{~cm}^{-1}$, respectively. This band is generally associated with the $\mathrm{N}$ $\mathrm{H}$ stretching vibration and shows the existence of hydrogen bonds. Doyle et al. [33] reported that a free N-H stretching vibration commonly occurs in the range of $3400-3440 \mathrm{~cm}^{-1}$. When the $\mathrm{NH}$ group of a peptide is involved in a hydrogen bond, the position is shifted to lower frequencies. Amide B band of SC $\left(2921 \mathrm{~cm}^{-1}\right)$ and CC $\left(2933 \mathrm{~cm}^{-1}\right)$ was related to asymmetrical stretch of $\mathrm{CH}_{2}$ stretching vibration [34]. The differences in wavenumber and amplitude of amides $\mathrm{A}$ and $\mathrm{B}$ found in SC and CC indicated that secondary structure of both collagens might be different in some extents.

Amides I, II, and III peak of SC was found at wavenumber of 1643,1541 , and $1233 \mathrm{~cm}^{-1}$, respectively. Payne and Veis reported that [35] amide I peak associated with $\mathrm{C}=\mathrm{O}$ stretching vibration or hydrogen bond coupled with $\mathrm{COO}^{-}$. Moreover, it is a sensitive marker for the secondary structure of proteins analysis in FTIR analysis [36], while amide II peak resulted from $\mathrm{N}-\mathrm{H}$ bending vibration coupled with $\mathrm{CN}$ stretching vibration [37]. Generally, amides I, II and III of peptide linkage have been found at 1600-1690, 1480-1575, and $1229-1301 \mathrm{~cm}^{-1}$, respectively [37]. Muyonga et al. [32] reported that shifts of amides I, II, and III peaks to lower wavenumbers are associated with increased intermolecular interactions (by hydrogen bonding) in collagen. The ratio between amide III and $1454 \mathrm{~cm}^{-1}$ peak of SC was 1.02 . Generally, the ratio of approximately 1.0 reveals the triplehelical structure of collagens [38]. The result indicated that the triple helical structure might be slightly affected by pepsin digestion during collagen extraction. When pepsin cleaved telopeptide regions of tropocollagen, the secondary structure of the resulting PSC might be altered to some degree [24, 39]. Collagen from the skin of splendid squid exhibited absorptions at 1031, 1060, and $1081 \mathrm{~cm}^{-1}$, which arise from the $\mathrm{C}-\mathrm{OH}$ stretching vibrations of the carbohydrate moieties attached to the protein [40]. The similar result was also found in CC. The result suggested that the collagens might contain carbohydrates, which are attached to hydroxylysine residues of the polypeptide chain by O-glycosidic bonds. The result was also in accordance with total sugar content (Table 1).

3.5. Peptide Mapping of SC and CC. The peptide maps of SC digested by chymotrypsin or lysyl endopeptidase, in comparison with that of CC, are shown in Figure 4. Major components, including $\alpha, \beta$-, $\gamma$-chains and high-MW crosslinked components, of SC were hydrolysed into degradation peptides with MW of $68.3,53.2,47.8,38.7$, and $34.7 \mathrm{kDa}$ and low MW peptides (Lane 4), whilst CC was hydrolysed into MW 108.6, 100.4, 85.5, 71.9, 67.4, and 38.7 kDa and low MW components after being treated with chymotrypsin (Lane 5). For peptide maps of collagens digested by lysyl endopeptidase, major components of CC were much degraded into lower MW peptides, especially peptides with $\mathrm{MW}$ of $33.8 \mathrm{kDa}$ and lower MW components (Lane 6). In contrast, lower number of degradation bands was found in SC (Lane 7).

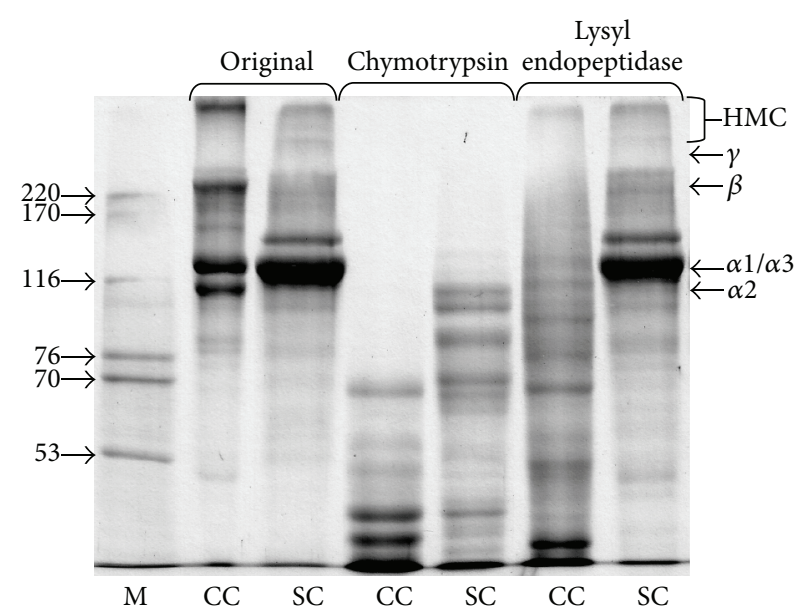

Figure 4: Peptide maps of collagen from the skin of splendid squid (SC) and type I collagen from calf skin (CC) digested by lysyl endopeptidase or chymotrypsin. $\mathrm{M}$ and HMC denote highMW protein markers and high-MW cross-linked components, respectively.

The result suggested that SC was more tolerant to hydrolysis by lysyl endopeptidase than CC. This might be due to the higher content of lysine in CC (Table 2). Chymotrypsin catalyses the hydrolysis of peptide bonds on the carboxyl side of hydrophobic amino acid residues, such as phenylalanine, tyrosine, tryptophan, and leucine [41], whilst lysyl endopeptidase prefers to hydrolyse peptide bonds at the carboxyl side of lysyl residues [42]. Due to the specificity of cleavage sites of both proteases, the marked difference in peptide maps of $\mathrm{SC}$ and $\mathrm{CC}$ was observed. The result revealed that primary structure of SC and CC was completely different, especially in terms of their sequence and the composition of amino acids.

\section{Conclusion}

Collagen could be extracted from the skin of splendid squid with the aid of pepsin. The resultant collagen was glycoprotein and comprised SQ-I and SQ-II components. However, identification of collagen type using additional separating technique or immunochemical detection or enzymatic treatment should be further conducted. The information gained from this study is beneficial for utilisation of squid skin byproduct in food, nutraceutical and cosmetic applications.

\section{Conflict of Interests}

The authors declare that there is no conflict of interests regarding the publication of this paper.

\section{Acknowledgments}

This work was supported by the Thailand Research Fund (TRF) and Office of the Higher Education Commission for Project no. MRG5680116 to Dr. Sitthipong Nalinanon and the TRF Distinguished Research Professor Grant. The authors 
would like to express their appreciation to King Mongkut's Institute of Technology Ladkrabang for support.

\section{References}

[1] E. A. Foegeding, T. C. Lanier, and H. O. Hultin, "Characteristics of edible muscle tissues," in Food Chemistry, O. R. Fennema, Ed., pp. 879-942, Marcel Dekker, New York, NY, USA, 1996.

[2] P. Kittiphattanabawon, S. Benjakul, W. Visessanguan, H. Kishimura, and F. Shahidi, "Isolation and Characterisation of collagen from the skin of brownbanded bamboo shark (Chiloscyllium punctatum)," Food Chemistry, vol. 119, no. 4, pp. 1519-1526, 2010.

[3] J. H. Muyonga, C. G. B. Cole, and K. G. Duodu, "Characterisation of acid soluble collagen from skins of young and adult Nile perch (Lates niloticus)," Food Chemistry, vol. 85, no. 1, pp. 81-89, 2004.

[4] D. W. S. Wong, Mechanism and Theory in Food Chemistry, Van Nostrand Reinhold Company Inc, New York, NY, USA, 1989.

[5] M. Ogawa, M. W. Moody, R. J. Portier, J. Bell, M. A. Schexnayder, and J. N. Losso, "Biochemical properties of black drum and sheepshead seabream skin collagen," Journal of Agricultural and Food Chemistry, vol. 51, no. 27, pp. 8088-8092, 2003.

[6] M. Sadowska, I. Kołodziejska, and C. Niecikowska, "Isolation of collagen from the skins of Baltic cod (Gadus morhua)," Food Chemistry, vol. 81, no. 2, pp. 257-262, 2003.

[7] S. Nalinanon, S. Benjakul, and H. Kishimura, "Characterization of collagen from the skin of unicorn leatherjacket (Aluterus monoceros) solubilized by albacore tuna pepsin," King Mongkut's Agro-Industry Journal, vol. 3, no. 1, pp. 53-70, 2011.

[8] S. Nalinanon, S. Benjakul, and H. Kishimura, "Collagens from the skin of arabesque greenling (Pleurogrammus azonus) solubilized with the aid of acetic acid and pepsin from albacore tuna (Thunnus alalunga) stomach," Journal of the Science of Food and Agriculture, vol. 90, no. 9, pp. 1492-1500, 2010.

[9] R. Duan, J. Zhang, X. Du, X. Yao, and K. Konno, "Properties of collagen from skin, scale and bone of carp (Cyprinus carpio)," Food Chemistry, vol. 112, no. 3, pp. 702-706, 2009.

[10] L. Wang, X. An, Z. Xin, L. Zhao, and Q. Hu, "Isolation and characterization of collagen from the skin of deep-sea redfish (Sebastes mentella)," Journal of Food Science, vol. 72, no. 8, pp. E450-E455, 2007.

[11] P. Kittiphattanabawon, S. Benjakul, W. Visessanguan, T. Nagai, and M. Tanaka, "Characterisation of acid-soluble collagen from skin and bone of bigeye snapper (Priacanthus tayenus)," Food Chemistry, vol. 89, no. 3, pp. 363-372, 2005.

[12] S. Nalinanon, S. Benjakul, W. Visessanguan, and H. Kishimura, "Use of pepsin for collagen extraction from the skin of bigeye snapper (Priacanthus tayenus)," Food Chemistry, vol. 104, no. 2, pp. 593-601, 2007.

[13] T. Nagai, K. Nagamori, E. Yamashita, and N. Suzuki, "Collagen of octopus Callistoctopus arakawai arm," International Journal of Food Science and Technology, vol. 37, no. 3, pp. 285-289, 2002.

[14] T. Nagai, E. Yamashita, K. Taniguchi, N. Kanamori, and N. Suzuki, "Isolation and characterisation of collagen from the outer skin waste material of cuttlefish (Sepia lycidas)," Food Chemistry, vol. 72, no. 4, pp. 425-429, 2001.

[15] M. Nagarajan, S. Benjakul, T. Prodpran, P. Songtipya, and H. Kishimura, "Characteristics and functional properties of gelatin from splendid squid (Loligo formosana) skin as affected by extraction temperatures," Food Hydrocolloids, vol. 29, no. 2, pp. 389-397, 2012.
[16] E. Fournier, "Basic protocol: determination of reducing and nonreducing sugars using the phenol-sulfuric acid assay," in Handbook of Food Analytical Chemistry, R. E. Wrolstad, T. E. Acree, E. A. Decker et al., Eds., pp. 653-655, John Wiley \& Sons, Hoboken, NJ, USA, 2005.

[17] U. K. Laemmli, "Cleavage of structural proteins during the assembly of the head of bacteriophage T4," Nature, vol. 227, no. 5259, pp. 680-685, 1970.

[18] B. J. Rigby, "Amino-acid composition and thermal stability of the skin collagen of the antarctic ice-fish," Nature, vol. 219, no. 5150, pp. 166-167, 1968.

[19] H. D. Belitz, W. Grosch, and P. Schieberle, Food Chemistry, Springer, Berlin, Germany, 2009.

[20] M. Saito, N. Kunisaki, N. Urano, and S. Kimura, "Collagen as the major edible component of sea cucumber (Stichopus japonicus)," Journal of Food Science, vol. 67, no. 4, pp. 1319-1322, 2002.

[21] P. Kittiphattanabawon, S. Benjakul, W. Visessanguan, and F. Shahidi, "Isolation and properties of acid- and pepsin-soluble collagen from the skin of blacktip shark (Carcharhinus limbatus)," European Food Research and Technology, vol. 230, no. 3, pp. 475-483, 2009.

[22] T. Nagai, N. Suzuki, and T. Nagashima, "Collagen from common minke whale (Balaenoptera acutorostrata) unesu," Food Chemistry, vol. 111, no. 2, pp. 296-301, 2008.

[23] A. M. Pearson and R. B. Young, Muscle and Meat Biochemistry, Academic Press Inc, San Diego, Calif, USA, 1989.

[24] S. Benjakul, Y. Thiansilakul, W. Visessanguan et al., "Extraction and characterisation of pepsin-solubilised collagens from the skin of bigeye snapper (Priacanthus tayenus and Priacanthus macracanthus)," Journal of the Science of Food and Agriculture, vol. 90, no. 1, pp. 132-138, 2010.

[25] K. A. Piez and J. Gross, "The amino acid composition of some fish collagens: the relation between composition and structure," The Journal of Biological Chemistry, vol. 235, no. 4, pp. 995-998, 1960.

[26] D. Liu, G. Wei, T. Li et al., "Effects of alkaline pretreatments and acid extraction conditions on the acid-soluble collagen from grass carp (Ctenopharyngodon idella) skin," Food Chemistry, vol. 172, pp. 836-843, 2015.

[27] S. Mizuta, R. Yoshinaka, M. Sato, and M. Sakaguchi, "Isolation and partial characterization of two distinct types of collagen in the squid Todarodes pacificus," Fisheries Science, vol. 60, no. 4, pp. 467-471, 1994.

[28] S. Kimura, Y. Takema, and M. Kubota, “Octopus skin collagen. Isolation and characterization of collagen comprising two distinct alpha chains," The Journal of Biological Chemistry, vol. 256, no. 24, pp. 13230-13234, 1981.

[29] G. Balian and J. H. Bowes, "The structure and properties of collagen," in The Science and Technology of Gelatin, A. G. Ward and A. Courts, Eds., pp. 1-31, Academic Press, London, UK, 1977.

[30] M. Ahmad, S. Benjakul, and S. Nalinanon, "Compositional and physicochemical characteristics of acid solubilized collagen extracted from the skin of unicorn leatherjacket (Aluterus monoceros)," Food Hydrocolloids, vol. 24, no. 6-7, pp. 588-594, 2010.

[31] S. Nalinanon, S. Benjakul, H. Kishimura, and K. Osako, "Type I collagen from the skin of ornate threadfin bream (Nemipterus hexodon): characteristics and effect of pepsin hydrolysis," Food Chemistry, vol. 125, no. 2, pp. 500-507, 2011. 
[32] J. H. Muyonga, C. G. B. Cole, and K. G. Duodu, "Fourier transform infrared (FTIR) spectroscopic study of acid soluble collagen and gelatin from skins and bones of young and adult Nile perch (Lates niloticus)," Food Chemistry, vol. 86, no. 3, pp. 325-332, 2004.

[33] B. B. Doyle, E. R. Blout, and E. G. Bendit, "Infrared spectroscopy of collagen and collagen like polypeptides," Biopolymers, vol. 14, no. 5, pp. 937-957, 1975.

[34] Y. Abe and S. Krimm, "Normal vibrations of crystalline polyglycine I," Biopolymers-Peptide Science Section, vol. 11, no. 9, pp. 1817-1839, 1972.

[35] K. J. Payne and A. Veis, "Fourier transform IR spectroscopy of collagen and gelatin solutions: deconvolution of the amide I band for conformational studies," Biopolymers, vol. 27, no. 11, pp. 1749-1760, 1988.

[36] W. K. Surewicz and H. H. Mantsch, "New insight into protein secondary structure from resolution-enhanced infrared spectra," Biochimica et Biophysica Acta (BBA), vol. 952, no. 2, pp. 115-130, 1988.

[37] S. Krimm and J. Bandekar, "Vibrational spectroscopy and conformation of peptides, polypeptides, and proteins," Advances in Protein Chemistry, vol. 38, pp. 181-364, 1986.

[38] A. M. D. G. Plepis, G. Goissis, and D. K. Das-Gupta, "Dielectric and pyroelectric characterization of anionic and native collagen," Polymer Engineering and Science, vol. 36, no. 24, pp. 29322938, 1996.

[39] P. Kittiphattanabawon, S. Benjakul, W. Visessanguan, and F. Shahidi, "Isolation and characterization of collagen from the cartilages of brownbanded bamboo shark (Chiloscyllium punctatum) and blacktip shark (Carcharhinus limbatus)," LWTFood Science and Technology, vol. 43, no. 5, pp. 792-800, 2010.

[40] C. Petibois, G. Gouspillou, K. Wehbe, J.-P. Delage, and G. Déléris, "Analysis of type I and IV collagens by FT-IR spectroscopy and imaging for a molecular investigation of skeletal muscle connective tissue," Analytical and Bioanalytical Chemistry, vol. 386, no. 7-8, pp. 1961-1966, 2006.

[41] R. Boyer, "Enzyme II: cofactors, regulation and catalytic RNA," in Conceptes in Biochemistry, R. Boyer, Ed., p. 178, John Wiley \& Sons, 2006.

[42] P. A. Jekel, W. J. Weijer, and J. J. Beintema, "Use of endoproteinase Lys-C from Lysobacter enzymogenes in protein sequence analysis," Analytical Biochemistry, vol. 134, no. 2, pp. 347-354, 1983. 

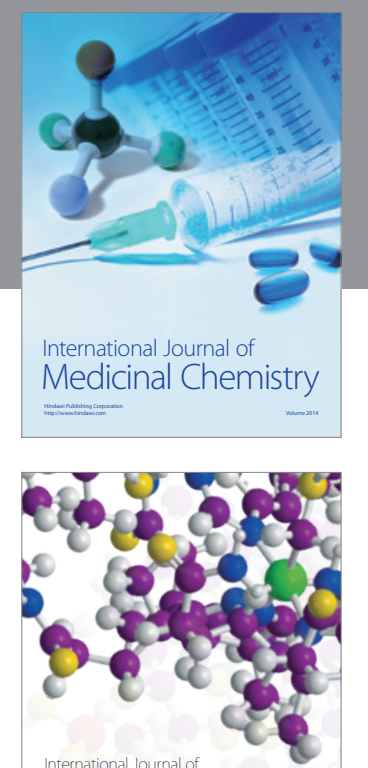

\section{Carbohydrate} Chemistry

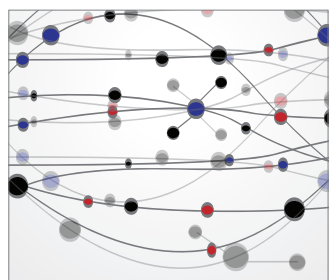

The Scientific World Journal
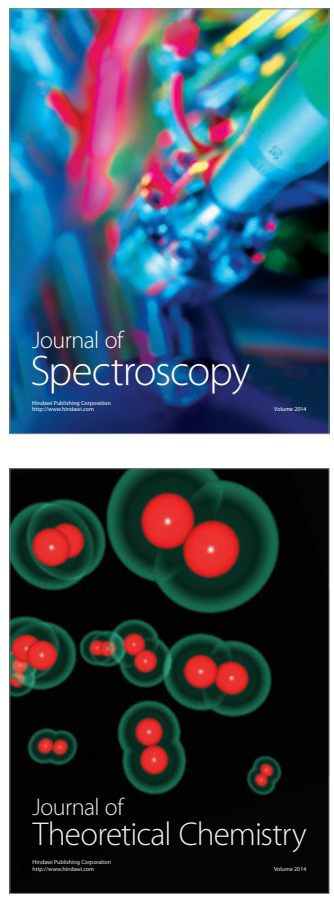
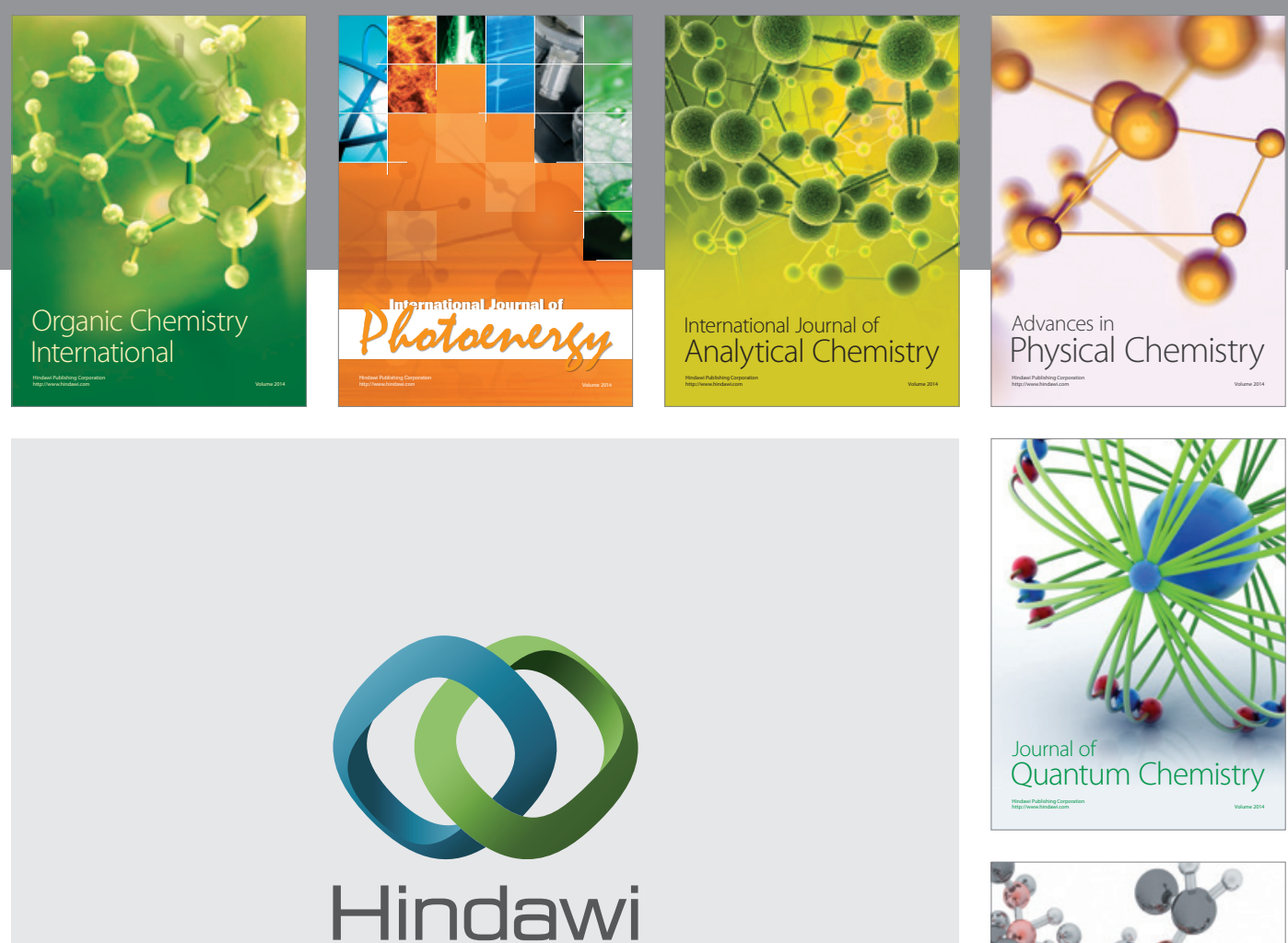

Submit your manuscripts at

http://www.hindawi.com

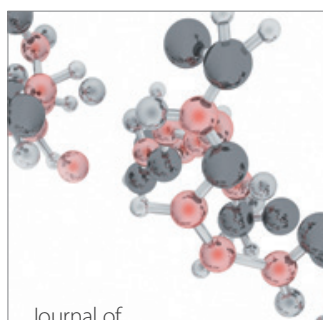

Analytical Methods

in Chemistry

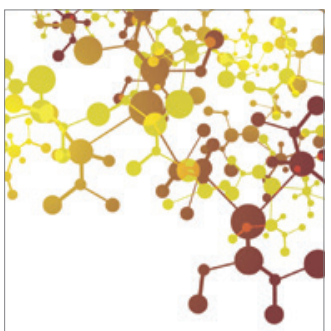

Journal of

Applied Chemistry

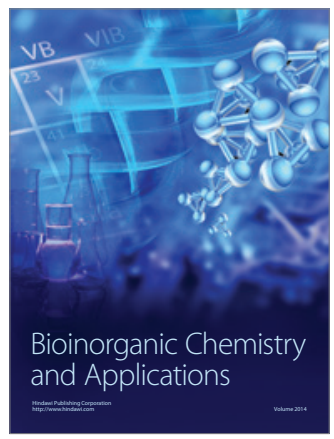

Inorganic Chemistry
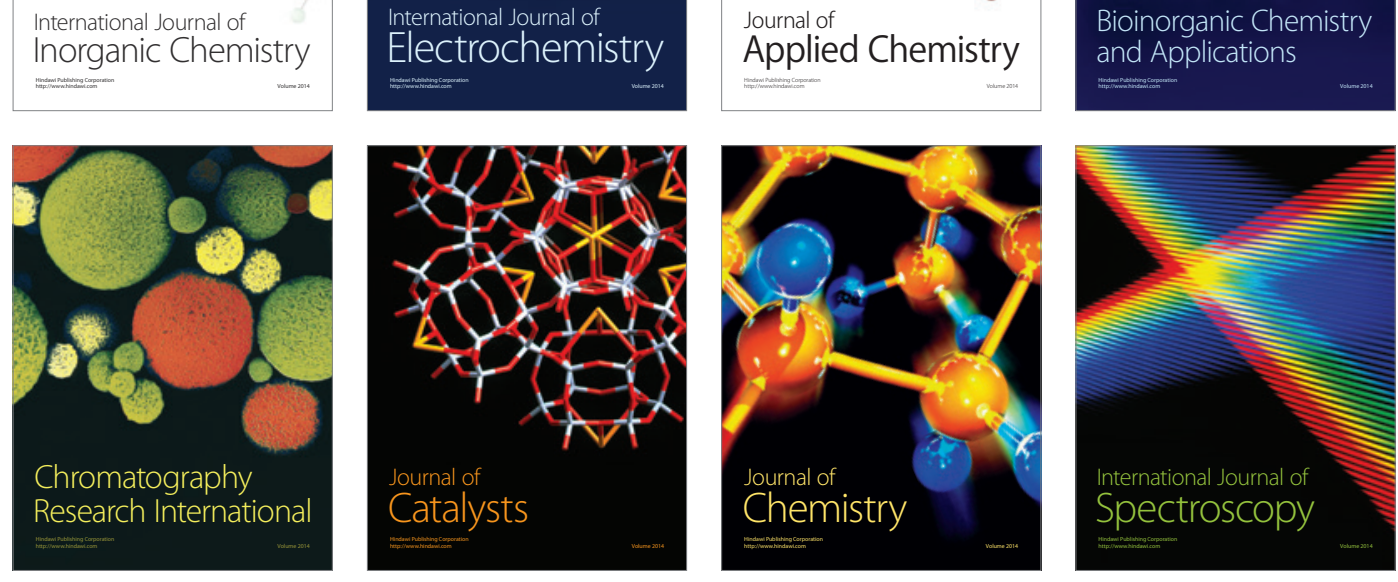